УДК 378

13.00.00 Педагогические науки

ВЫСШЕЕ ТЕХНИЧЕСКОЕ ОБРАЗОВАНИЕ: ОСОБЕННОСТИ И ПЕРСПЕКТИВЫ РАЗВИТИЯ

Бедерханова Вера Петровна доктор педагогических наук, профессор, профессор кафедры социальной работы, психологии и педагогики Vpb57@mail.ru РИНЦ SPIN-код 4729-2767

Кубанский государственный университет, Краснодар, Россия

В статье раскрываются характерные черты технического образования. Показано, что особенностью технических знаний является то, что они базируются на соответствующем типе мышления и направлены на разработку, создание и применение технических средств и

технологических процессов. Раскрыты главные отличия высшего технического образования, заключающиеся в развитии абстрактного представления физических процессов, умения оперативно принимать решения, в широком охвате специализаций в процессе обучения. Предложен комплекс организационно-методических мероприятий, направленный на повышение качества образования выпускников технических вузов

КЛючевые слова: ТЕХНИЧЕСКОЕ

ОБРАЗОВАНИЕ, ТЕХНИЧЕСКОЕ МЫШЛЕНИЕ, КАЧЕСТВО ОБРАЗОВАНИЯ, СИСТЕМА ИНЖЕНЕРНОЙ ПОДГОТОВКИ
UDC 378

Pedagogical sciences

\section{TECHNICAL UNIVERSITY EDUCATION: FEATURES AND PROSPECTS OF DEVELOPMENT}

Bederkhanova Vera Petrovna

Doctor of pedagogical Sciences, Professor, Department of social work, psychology and pedagogy Vpb57@mail.ru

RSCI-SPIN-code 4729-2767

Kuban state University, Krasnodar, Russia

The article describes the characteristic features of technical education. It shows that the main characteristics of technical knowledge is that they are based on the corresponding type of thinking and focused on the development, creation and use of technical means and technological processes. We have revealed the main differences of higher technical education, namely the development of abstract representations of physical processes, the ability to make decisions quickly in a wide scope of specializations in the learning process. The work proposes a set of organizational and methodological measures aimed at improving the quality of education of graduates of technical universities

Keywords: TECHNICAL EDUCATION, TECHNICAL THINKING, QUALITY OF EDUCATION, SYSTEM OF ENGINEERING TRAINING

Doi: 10.21515/1990-4665-132-114

В настоящее время укрепление и развитие высшего технического образования стало стратегическим приоритетом для многих стран. Ставка здесь высокая - глобальная конкурентоспособность и геополитическое выживание. В 2010 г. в Китае количество студентов, обучающихся по инженерным программам 1-го уровня (бакалавриат), составляло около 1,32 млн чел, что в 1,4 раза больше, чем в странах Европы и 2,4 раза больше, чем в США [4]. Это способствовало в кратчайшие сроки значительно повысить уровень экономического развития страны. 
В России, по данным мониторинга 2015 г. (показатели 900 вузов и 1232 их филиалов) было установлено, что образование по программам, относящимся к области «Инженерное дело, технологии и технические науки», получили 29,4 \% (850 тыс. чел.) от всего контингента российских студентов [8]. Эта цифра практически сопоставима с соответствующими показателями ведущих стран мира.

Развития системы инженерной подготовки специалистов технических вузов диктуют ускоренные темпы научно-технического прогресса. От специалистов технических и технологических специальностей (далее - технических) зависит уровень экономического развития государства.

В настоящее время сложилась следующая классификация наук: технические, естественные, общественные, гуманитарные и точные. Поскольку система образования строится исходя из классификации наук, то важно определить особенности и направления развития системы технического образования, которое оказывает существенное влияние на экономический уровень развития страны.

Исторически определяющим фактором развития технических наук был процесс становления научно технического знания, в ходе которого на основе результатов наблюдения и исследования была построена техническая теория. Таким образом, возникновению научно-технических знаний послужили экспериментальные опыты, исследующие законы природы. Техническое знание существенно отличается от других наук, так как оно всегда связано с техническим объектом. Кроме того, технический объект является искусственным, созданным для определённой цели, которой и подчинены его конструкция и функции.

Во всех своих объектах исследований технические науки определяют связь устройства и его функций. Эта задача обусловлена назначением технических наук - раскрыть субъективные и объективные компоненты 
работоспособности и связи между ними, которые обеспечивают требуемый результат.

Прогресс в технических знаниях заключается в развитии технического творчества, заключающегося в разработке (конструировании) того, чего еще не было, или в модернизации (улучшении характеристик) того, что известно. Овладение методологией творческой деятельности, проектирования и предвидения возможных последствий будущей профессиональной деятельности становится одним из важнейших направлений технического образования.

Техническое мышление направлено на решение теоретических и практических задач. Цель теоретического мышления - открытие законов, свойств объектов, практическое мышление - это процесс, совершающийся в ходе практической деятельности. Отличительной особенностью технического образования является тесная связь образовательного процесса с практикой.

Таким образом, во-первых, характерной чертой технических знаний является их базирование на техническом мышлении и направленность на решение конструктивных и технологических задач, изучение функционирования технических объектов и систем.

Во-вторых, техническое творчество, развитию которого должно способствовать техническое знание, направлено на разработку, создание и применение технических средств и технологических процессов. Главное качество технического мышления заключается в том, что оно включается в практическую производственную деятельность и осуществляется исходя из реальных условий этой деятельности.

В общем случае под термином «техническое образование» понимают, как правило, совокупность научно-технических и практических знаний, позволяющих решать производственно-технические, технологические, экономические и другие задачи. Однако в парадигме 
личностно ориентированной педагогики существует новое понимание образованности: «не просто многознание и владение набором профессиональных навыков, а именно развитие многообразных способностей системного характера и высокой степени их продуктивности» [3, 127]. Известно, что флагманами технического образования являются технические университеты. «В отличие от классического, технический университет ориентирован на подготовку профессионалов, являющихся носителями целостной системной профессиональной деятельности, способных воспринять идеи устойчивого развития цивилизации и реализовать их в профессиональной сфере, а также обладающих повышенным уровнем культуры, творческим потенциалом, обеспечивающим их успешную профессиональную деятельность в условиях доминирования наукоёмких, интеллектоёмких и инновационных технологий» $[11,32]$. Качество образования выпускников технических вузов зависит от уровня знаний у набранного контингента обучающихся, их способностей и наклонностей к усвоению специальных дисциплин. Эта предрасположенность должна определяться за несколько лет до окончания среднего образовательного учреждения путем решения специальных тестовых заданий, определяющих склонность к той или иной специальности (профессиональный отбор). Для технического образования профилирующими школьными предметами являются математика и физика, для некоторых специальностей - и химия. После анализа итогов тестирования обучение школьников должно строиться с большей направленностью на изучение предметов, по которым показаны лучшие результаты [6].

Процесс технического образования тесно связан с получением практических навыков, без которых оно теряет ценность. Поэтому особое место в учебном процессе принадлежит практическим занятиям, на которых изучаются технологические процессы, устройства, системы и 
прививаются навыки исследовательской работы (на лабораторных занятиях, в период выполнениях контрольных, курсовых работ и проектов), развивающие творческие способности.

Важная роль принадлежит изучению компьютерной техники и применению программных продуктов для решения профессиональных задач. Сегодня компьютерные технологии являются неотъемлемой частью учебного процесса, студенты приобретают навыки работы с разными программами, проведения исследований физических процессов, протекающих в сложных электрических цепях, механизмах или системах. Имеющееся оборудование не всегда используется для проведения исследований, как правило, из-за его высокой стоимости. С помощью компьютера и специальных программ можно проводить виртуальные исследования физических процессов, что способствует повышению эффективности образовательного процесса.

Навыки проведения самостоятельных исследований, в том числе решения профессиональных задач, закрепляются в процессе работы студентов в научно-исследовательских кружках. При этом расширяется кругозор обучающихся, приобретается умение работать в научных и производственных коллективах, формируются навыки самостоятельной учебы с использованием современных средств получения научнотехнической информации $[4,6]$.

Особое место в учебном процессе технических вузов принадлежит лабораторным занятиям, где учебная группа разбивается на бригады, как правило, от 3 до 5 студентов. С одной стороны, на этих занятиях приобретаются навыки проведения исследований (сбора схем, снятия показаний измерительных приборов, проведения расчетов, построения графиков, анализа результатов, формирования правильных выводов), а с другой - формируется умение работы в коллективе. В ходе целенаправленного общения обучающихся и преподавателей, студенты 
учатся формулировать и обосновывать свою точку зрения, доказывать свою правоту, развивают навыки публичных выступлений во время защиты отчета по лабораторной работе. Таким образом, лабораторные занятия способствуют не только развитию технического творческого мышления, но и формируют определенные управленческие навыки, необходимые для будущих руководителей организаций и предприятий.

Так, одним из видов занятий, который позволяет развивать организационные способности - основное качество руководителя, являются методические занятия под руководством преподавателя. Такие занятия должны проводиться на старших курсах бакалавриата и в магистратуре по дисциплинам специальности. На этих занятиях студенты выступают в роли руководителя занятия и проводят обучение своих коллег по одному из несложных вопросов изучаемой дисциплины [6].

Организаторские способности у студентов развиваются не только на методических занятиях, но и когда они выступают в роли старшего бригады во время лабораторных занятий, выполняют обязанности старосты группы, выполняют общественные поручения, организуя спортивно-оздоровительные и культурно-массовые мероприятия. Организаторские способности обуславливают высокую результативность принимаемых решений, позволяют эффективно действовать в стандартных и нестандартных ситуациях, оптимально использовать материальные и кадровые ресурсы.

Чтобы выпускники современных технических вузов обладали необходимыми компетенциями и были востребованы на рынке труда, необходимо, чтобы их педагоги владели не только современными знаниями техники и производственных технологий, но и постоянно совершенствовали технологии преподавания дисциплин, применяя современные технические средства и методики обучения $[3,6]$. 
Несформированность важных интеллектуальных навыков современных студентов, в частности неумение связно формулировать мысли, логически аргументировать высказанные предложения, говорить в ходе беседы профессиональным языком, используя термины специальности. Эти проблемы в современном вузе ликвидируются при использовании активных и интерактивных методов обучения («круглый стол», мозговой штурм, деловая игра, методические занятия под руководством преподавателя) во время проведения практических и лабораторных занятий, защиты курсовых работ и проектов, а также выпускных квалификационных работ.

Интерактивные методы обучения - одно из эффективных средств образовательного процесса, способствующее повышению качества подготовки студентов за счет привития им навыков будущих руководителей. Практика показала, что лучше всего студенты запоминают материал в том случае, когда они не только слушают, но ещё и выполняют какие-то действия (конспектируют, рисуют, работают с литературой, собирают схему и т. п.), общаясь при этом не только с преподавателем, но и между собой. Интерактивные методы обучения, в отличие от классических, позволяют решать в комплексе следующие задачи $[6,12]$ :

- формировать у студентов интерес к изучаемой дисциплине;

- повышать эффективность учебного процесса за счет коллективного обучения и творческого применения знаний;

- развивать аналитическое мышление и способность самостоятельно искать пути решения задачи (проблемы);

- формировать толерантность к мнению других членов коллектива;

- развивать навыки руководителя, благодаря опыту работы в коллективе (студенты учатся формировать собственное мнение, отношения, профессиональные и жизненные навыки). 
Повышаются требования и к преподавателям современных вузов. Не формальное, а реальное и постоянное повышение квалификации, расширение видов производственной и педагогической практики, овладение новыми информационными и образовательными технологиями, позволяющими решать научно-педагогические задачи и достигать учебных целей, становятся необходимым для преподавателя, чтобы обеспечивать тесное взаимодействие субъектов образовательного процесса - студентов и преподавателей, что будет способствовать высокому уровню интеграции технических знаний.

Неотъемлемой частью современного образовательного процесса являются оценка качества текущей подготовки студентов, оценка качества образования выпускников вузов и оценка эффективности деятельности профессорско-преподавательского состава [2, 7]. При оценке качества образования выпускников вуза должны учитываться результаты обучения, трудовой потенциал и квалификация преподавателей, которые проводивших занятия [7].

Анализ текущей успеваемости и качества образования выпускников вузов позволит оперативно вносить изменения в организацию учебного процесса и содержание рабочих программ обучения, а также учебнометодического и материально-технического обеспечения, изменять содержание и технологии повышения квалификации профессорскопреподавательского состава, что в комплексе будет способствовать повышению уровня востребованности выпускников вуза на рынке труда.

Кроме того, перспективы развития высшего технического образования связаны с внедрением в учебный процесс следующего комплекса организационно-методических мероприятий $[1,2,5,10]$.

1. Для соблюдения последовательности изучения дисциплин по темам и видам занятий расписание занятий должно составляться на семестр. 
2. С 2-го курса бакалавриата и 1-го курса магистратуры необходимо закреплять за студентами преподавателей-наставников, которые должны организовывать работу студентов в научно-исследовательских кружках и в перспективе быть руководителями их выпускных квалификационных работ.

3. В ходе изучения дисциплин специализации должны использоваться активные и интерактивные методы обучения, в том числе методические занятия, проводимые студентами под руководством преподавателя.

4. Оценка качества текущей подготовки студентов и выпускников вуза должна проводиться с учетом квалификации преподавателей, проводивших занятия.

5. Студенты, которые по результатам текущей успеваемости имели средний балл 4,5 и выше должны освобождаться от зачетов и экзаменов по дисциплине с выставлением оценок «5», и «4», если средний балл находится в пределах 4,0-4,4 (в последнем случае - по их просьбе, если студент не претендует на оценку «5»).

6. Объективность оценки качества подготовки группы (курса) можно повысить, если учитывать квалификацию преподавателей, проводивших занятия и использовать три критерия: общую оценку по дисциплине, средний балл по результатам экзамена (зачёта) и процент положительных оценок («4» и «5»).

7. В учебном процессе по результатам текущего контроля знаний преподаватели при необходимости должны оперативно вносить изменения в содержание рабочих программ обучения.

8. При низких показателях текущих знаний студентов и выпускников вуза, в том числе при отрицательных отзывах работодателей, заведующий кафедрой должен вносить коррективы содержание и технологии повышения квалификации профессорско-преподавательского состава. 
9. Оценка качества образования выпускников вуза должна включать комплексный показатель их учебной и трудовой активности (результаты научно-исследовательской работы, награды, полученные за участие в спортивно-оздоровительных и культурно-массовых мероприятиях).

Внедрение в образовательный процесс рассмотренного комплекса организационно-методических мероприятий будет способствовать повышению качества образования и уровня востребованности выпускников технических вузов на рынке труда.

\section{Список литературы}

1. Анищенко В. С. Об опыте количественной оценки эффективности работы преподавателей в Саратовском национальном исследовательском университете / В. С. Анищенко, Е. Г. Елина // Alma mater (Вестник высшей школы). - 2015. - № 3. - С. 3037.

2. Аркаева Р. П. Квалиметрический подход в управлении качеством образования студентов / Р. П. Аркаева // Вектор науки ТГУ. - 2012. - № 1(8). - С. 38-40.

3. Бедерханова В. П. Становление личностно-ориентированной позиции педагога; Монография / В. П. Бедерханова. - Краснодар: КубГУ, 2001. - 220 с.

4. Бондырева И. Б. Координация взаимодействий субъектов интегрированного образовательного пространства при подготовке инженеров / И. Б. Бондарева // Многоуровневое общественное воспроизводство: вопросы теории и практики. - 2017. № 12 (28). - C. 21-34.

5. Бычкова Т. В. К вопросу применения экспертных оценок в мониторинге образования / Т. В. Бычкова // Человек и образование. - 2014. - № 1(38). - С. 138-142.

6. Григораш О. В. Система подготовки специалистов с высшим техническим образованием: монография / О. В. Григораш. - Краснодар: К КубГАУ, 2017. - 329 с.

7. Григораш О. В. Комплексная оценка качества подготовки студентов и эффективности деятельности кафедры: монография / О. В. Григораш, А. И. Трубилин. Краснодар: КубГАУ, 2017. - 185 с.

8. Меликян А. В. Статический анализ российской системы высшего образования / А. В. Меликян // Вопросы статистики. - 2017. - № 1. - С. 26-35).

10. Третьякова Н. В. Многомерный анализ качества профессиональной деятельности преподавателя высшей школы / Н. В. Третьякова, В. А. Федоров // Сибирский педагогический журнал. - 2015. - № 3. - С. 74-78.

11. Фёдоров И. Б. Становление и развитие системы университетского технического образования России / И.Б. Фёдоров, И. Б. Балтян // Высшее образование в России. - 2012. - №11. - С.-39.

\section{References}

1. Anishhenko V. S. Ob opyte kolichestvennoj ocenki jeffektivnosti raboty prepodavatelej $\mathrm{v}$ Saratovskom nacional'nom issledovatel'skom universitete / V. S. Anishhenko, E. G. Elina // Alma mater (Vestnik vysshej shkoly). - 2015. - № 3. - S. 30-37. 
2. Arkaeva R. P. Kvalimetricheskij podhod $\mathrm{v}$ upravlenii kachestvom obrazovanija studentov / R. P. Arkaeva // Vektor nauki TGU. - 2012. - № 1(8). - S. 38-40.

3. Bederhanova V. P. Stanovlenie lichnostno-orientirovannoj pozicii pedagoga; Monografija / V. P. Bederhanova. - Krasnodar: KubGU, 2001. - 220 s.

4. Bondyreva I. B. Koordinacija vzaimodejstvij sub\#ektov integrirovannogo obrazovatel'nogo prostranstva pri podgotovke inzhenerov / I. B. Bondareva // Mnogourovnevoe obshhestvennoe vosproizvodstvo: voprosy teorii i praktiki. - 2017. - № 12 (28). - S. 21-34.

5. Bychkova T. V. K voprosu primenenija jekspertnyh ocenok $\mathrm{v}$ monitoringe obrazovanija / T. V. Bychkova // Chelovek i obrazovanie. - 2014. - № 1(38). - S. 138-142.

6. Grigorash O. V. Sistema podgotovki specialistov s vysshim tehnicheskim obrazovaniem: monografija / O. V. Grigorash. - Krasnodar: KubGAU, 2017. - 329 s.

7. Grigorash O. V. Kompleksnaja ocenka kachestva podgotovki studentov i jeffektivnosti dejatel'nosti kafedry: monografija / O. V. Grigorash, A. I. Trubilin. Krasnodar: KubGAU, 2017. - 185 s.

8. Melikjan A. V. Staticheskij analiz rossijskoj sistemy vysshego obrazovanija / A. V. Melikjan // Voprosy statistiki. - 2017. - № 1. - S. 26-35).

10. Tret'jakova N. V. Mnogomernyj analiz kachestva professional'noj dejatel'nosti prepodavatelja vysshej shkoly / N. V. Tret'jakova, V. A. Fedorov // Sibirskij pedagogicheskij zhurnal. - 2015. - № 3. - S. 74-78.

11. Fjodorov I. B. Stanovlenie i razvitie sistemy universitetskogo tehnicheskogo obrazovanija Rossii / I.B. Fjodorov, I. B. Baltjan // Vysshee obrazovanie v Rossii. - 2012. №11. - S.-39. 